INTERNATIONAL DESIGN CONFERENCE - DESIGN 2018

https://doi.org/10.21278/idc.2018.0428

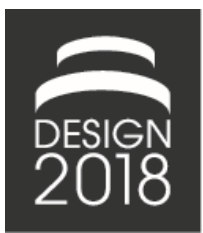

\title{
VIRTUAL AND MIXED PROTOTYPING TECHNIQUES AND TECHNOLOGIES FOR CONSUMER PRODUCT DESIGN WITHIN A BLENDED LEARNING DESIGN ENVIRONMENT
}

\author{
M. Bordegoni, F. Ferrise, R. Wendrich and S. Barone
}

\begin{abstract}
Both physical and virtual prototyping are core elements of the design and engineering process. In this paper, we present an industrial case-study in conjunction with a collaborative agile design engineering process and "methodology." Four groups of heterogeneous Post-doc and Ph.D. students from various domains were assembled and instructed to fulfill a multi-disciplinary design task based on a real-world industry use-case. We present findings, evaluation, and results of this study.
\end{abstract}

Keywords: virtual prototyping, virtual reality (VR), augmented reality (AR), engineering design, collaborative design

\section{Introduction}

Virtual and mixed prototyping within a collaborative blended learning environment is considered an enabling design support technique that allows designers to gain first-hand appreciation of existing or near-future conditions through active engagement with a wide variety in prototyping techniques and prototypes. The product design process (PDP) follows a dual approach and method based on a combination of a blended learning environment (Boelens et al., 2017) and interactive affective experience prototyping (Buchenau and Suri, 2000). The virtual prototyping summer school (VRPT-SS) facilitates this combinatorial collaborative setting to immerse learners in the externalization and representation of their ideas quickly, exploring and communicating their ideas with others. During the course of the week a series of evaluations on the prototyping progressions are made. The spectrum of virtual and mixed prototyping is quite extensive and has multiple definitions and meanings according to literature (see Wang, 2002, and Zorriassatine et al., 2003). In example: from typical digital representations generated through the use of computer-aided design tools or to their use through virtual, augmented or mixed reality technologies. The idea of virtual and mixed prototyping is the use of data of any digital nature through techniques and technologies of virtual- or augmented reality (as described in Bordegoni and Ferrise, 2013, and Ferrise et al., 2017). Every year at the Politecnico di Milano a VRPT-SS is organized for Ph.D. students and post-docs. We discuss virtual or augmented reality tools to support prototyping and generally talk about virtual or augmented reality technologies to support visual perceptive prototyping activities (i.e. for the sense of sight). Specifically, the summer school instead focuses on the integration of various and multiple senses in the prototyping activity. Consequently, since the first edition, it has been focused on all aspects of multisensory integration, and on the integration and application of all those technologies. Although these technologies are less developed than those of vision, they offer a complete representation of what the idea is in design. VRPTSS has always been focused on technologies for the sense of touch (i.e. tactile, haptics), hearing, and in 
the latest editions the sense of smell was included. Experts and instructors from different disciplines are involved in the school, ranging from engineering to product design to neuroscience and psychology, up to companies that can be classified as end users.

In the past, VRPT-SS, which lasts five days from Monday to Friday, was organized in lessons. Ten teachers were invited to give lectures of about three hours and students at the end of the course were evaluated on the basis of a paper on the use of these techniques and technologies in their own field of research. The students that participated in the school over the years came from the same domains as the experts and instructors, i.e. different disciplines of engineering, architectural- or industrial design, computer science, neuroscience, and psychology. Over the years a transformation in virtual or augmented reality technologies has been witnessed. From bulky and voluminous technologies, that required fixed installations, towards small and miniaturized technologies that can be integrated into an existing context. In fact, in the context of research more and more often we hear about mixed reality rather than virtual reality. Even the VRPT-SS has adapted to this trend and starting from the 2017 (8thedition) the school has been transformed into a design studio. Lectures were reduced to two and a half days out of five and in the remaining two and a half days the students were asked to integrate different mixed or augmented reality technologies within commonly used products, services and/or artefacts. In this last edition a real-world industrial case study was introduced as a design-brief. Four multidisciplinary groups were formed to collaboratively design, build, develop and prototype a consumer product and/or service. The case study was provided by a large sporting goods company namely Adidas. The execution of an agile collaborative design and engineering process for a commonly used object, stood as base for the design-task. In such a consumer backpack had to be translated and transformed into an experience, engaging and multisensory device, product or service. After a phase of lectures and instruction, the students had to generate ideas, starting from a simple project brief, and prototyping their own ideas (inspired by what is described in Buchenau and Suri, 2002). The results of the studio activities were very interesting, and in this paper, the school is analysed, trying to identify the key points that have led to the achievement of interesting results in such a short period of time.

\section{Design task and design phases}

\subsection{Design task}

\subsubsection{Design task industrial use-case and briefing}

The design task was the following: "...to conceptually design and prototype a consumer backpack translated and transformed into a contextualized- experience, engaging and multisensory device, product or service" (Figure 1). Adidas briefing was structured in the following way: a short historic perspective; a short description of the new 3-D Additive Manufacturing (3-D AM) shoe development process; something about traditions; strategic design; a description of the design phase in Adidas of six-eight week time-to-market; some top athlete scenarios; marketing branding; the interactive component; embedded technology; shape-weight-modelling-tactility-colour-textures; cost.

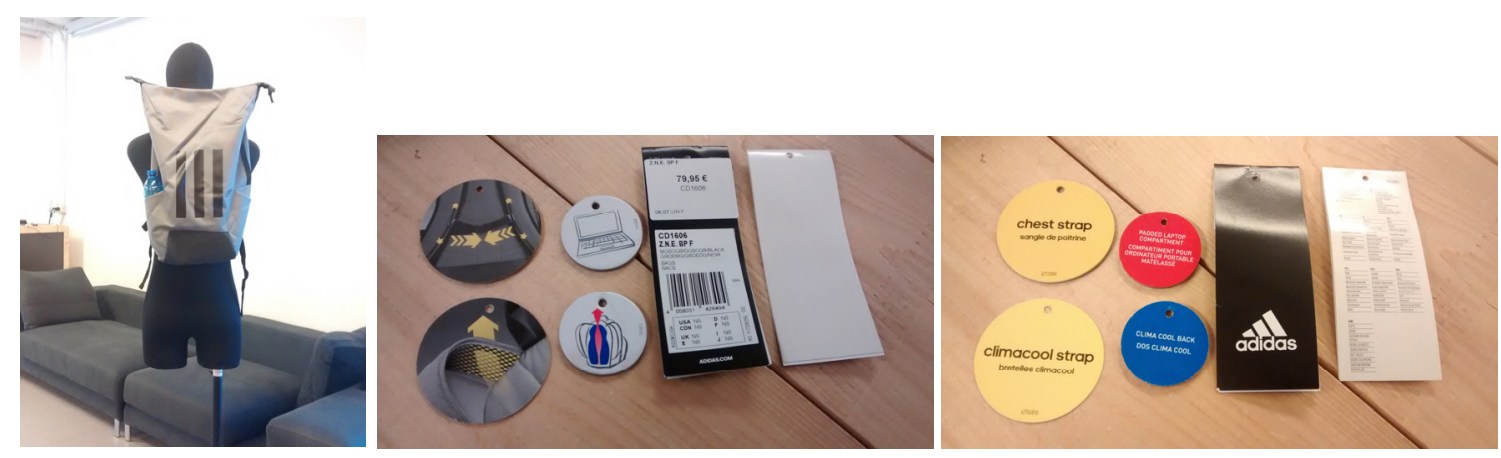

Figure 1. Adidas consumer product: Generic backpack, coding- and branding tags 

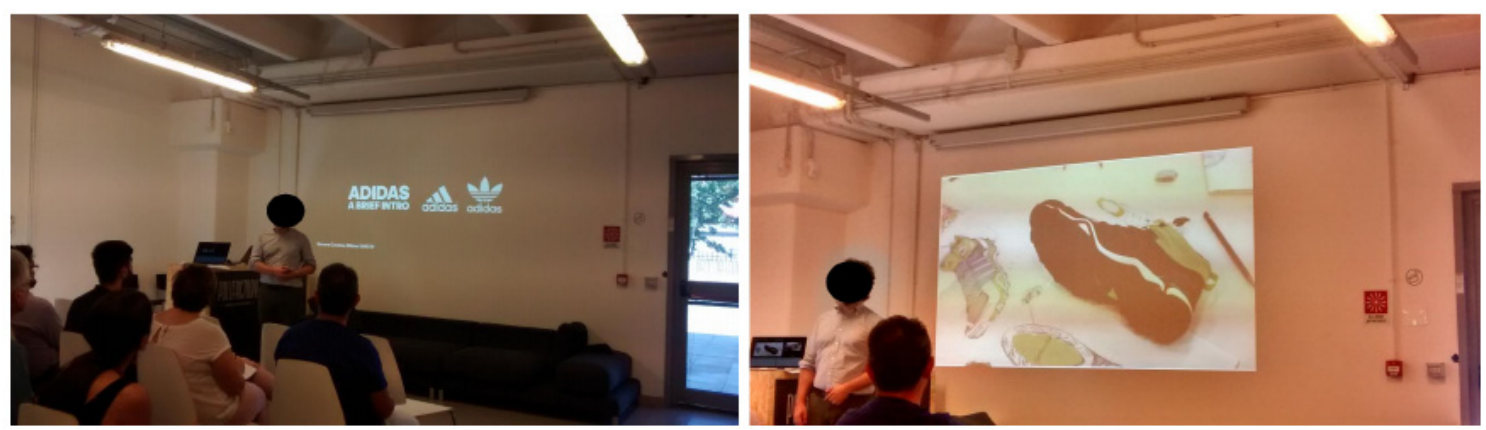

Figure 2. Briefing by Adidas design engineer on design task

\subsubsection{Encapsulated teaching expertise in design activity and task action}

After the introduction and briefing from Adidas on the first day of VRPT-SS (Figure 2), two lectures from academia were given on the topics of multi-sensory perception and experience design.

The second day three educational talks addressing fashion technology, design for additive manufacturing (AM) / 3D printing technology, and multi-sensory design were given (Figure 3). In the afternoon the first design phase in product concept development (i.e. ideation, conceptualization) started whereby all four groups worked collaboratively and shared ideas and notions amongst other groups continuously in order to speed up the idea-flow and iterative design process. Facilitators (i.e. experts) walked around and discussed upcoming and externalized ideas with the teams. Occasionally, the process was called to a halt and the teams were asked to present their prospective ideas on the fly, context, themes, and line of thinking were shared with the teaching experts and other teams (Figure 4) (see also Muraida and Spector, 1992; Alterator et al., 2017). This mode of working generates the transference, sharing, and crossover of preliminary ideas and develops the reflection-in-action, reflection-on action and thinking-by-doing process across all delegates and team-members. The actual early representation of ideas, sharing and conveying them from the onset are dominant features of any creative externalization and iterative course of action. Day three started with two lectures, one on haptic/tactile technology and another on sonic interaction design.
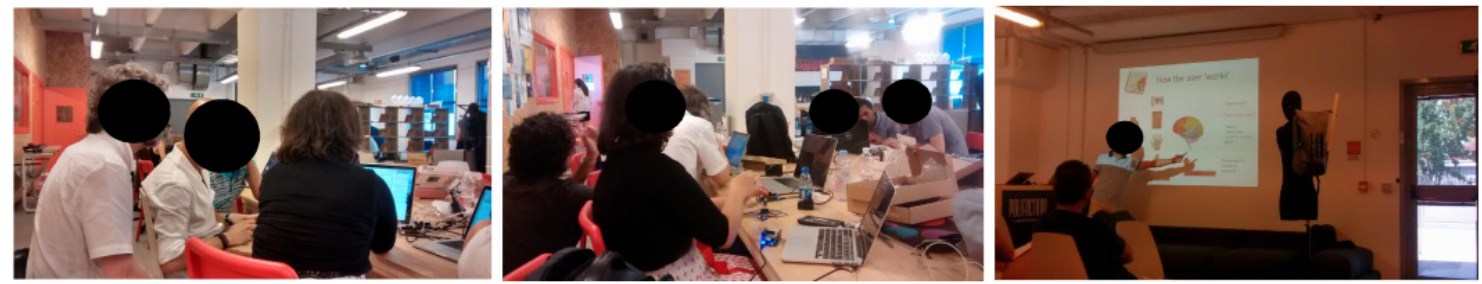

Figure 3. Experts and design teams in concurrent communication
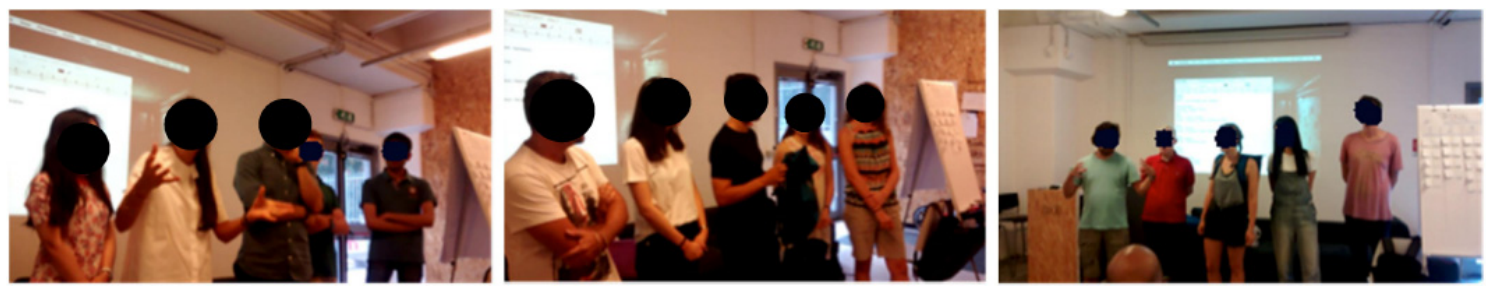

Figure 4. Intermediate team presentations 
The afternoon was reserved for further concept development in conjunction with early-stage lowresolution prototyping. Adidas supplied a number of generic backpacks to be used by the teams to hack, tinker, build, and construct possible solutions in relation to the specific design task. Several tech-kits with e.g. sensors, actuators, and PCB-boards were facilitated and used in mixed- or augmented reality scenarios and/or contexts. The last two days of the VRPT-SS week were mostly for final execution of the chosen concept and finalization of representations and presentation by the four teams.

\subsubsection{Collaborative groups and team building}

In order to facilitate the collaborative aspects of the VRPT-SS and to fulfil respectively the anticipated design task, groups were formed randomly from the multi-disciplinary student participants (Figure 4). A total of twenty $\mathrm{PhD}$ and Post-Doc students participated, nine females and eleven males. The looselyfitted agile setting of the school was also applied to the team-formations. The multidisciplinary teams consisted out of: designers (i.e. industrial, fashion, interaction domains), mechanical engineers, architects, computer science engineers, and construction engineers. During the course of the sessiondays all four teams were frequently team hopping to share and discuss information, ideas, thoughts and collaboratively work and prototype together on the common design task and problems in close collaboration with the teaching-experts. Team building that enhanced the social relations and defined the roles within teams evolved through engaging discussions and inspirational talks in combination with sufficient assistance and adequate support. Particularly important during product and prototype development sessions and/or sequences that are fast, agile, and have time-constraints working well together is more effective, more productive, and more successful-not to mention happier, playful, and more fun.

Team 1 consisted of 5 members: 4 female and 1 male students. Title of project design concept: 'Thief of the week.' Team 2 consisted of 4 members: 2 female and 2 male students. Title of project design concept: 'Follow your rhythm - A new running experience.' Team 3 consisted of 5 members: 2 female and 3 male students. Title of project design concept: 'Hut Hood.' Team 4 consisted of 6 members: 3 female and 3 male students. Title of project design concept: 'Backupack' (Figures 5 and 6).

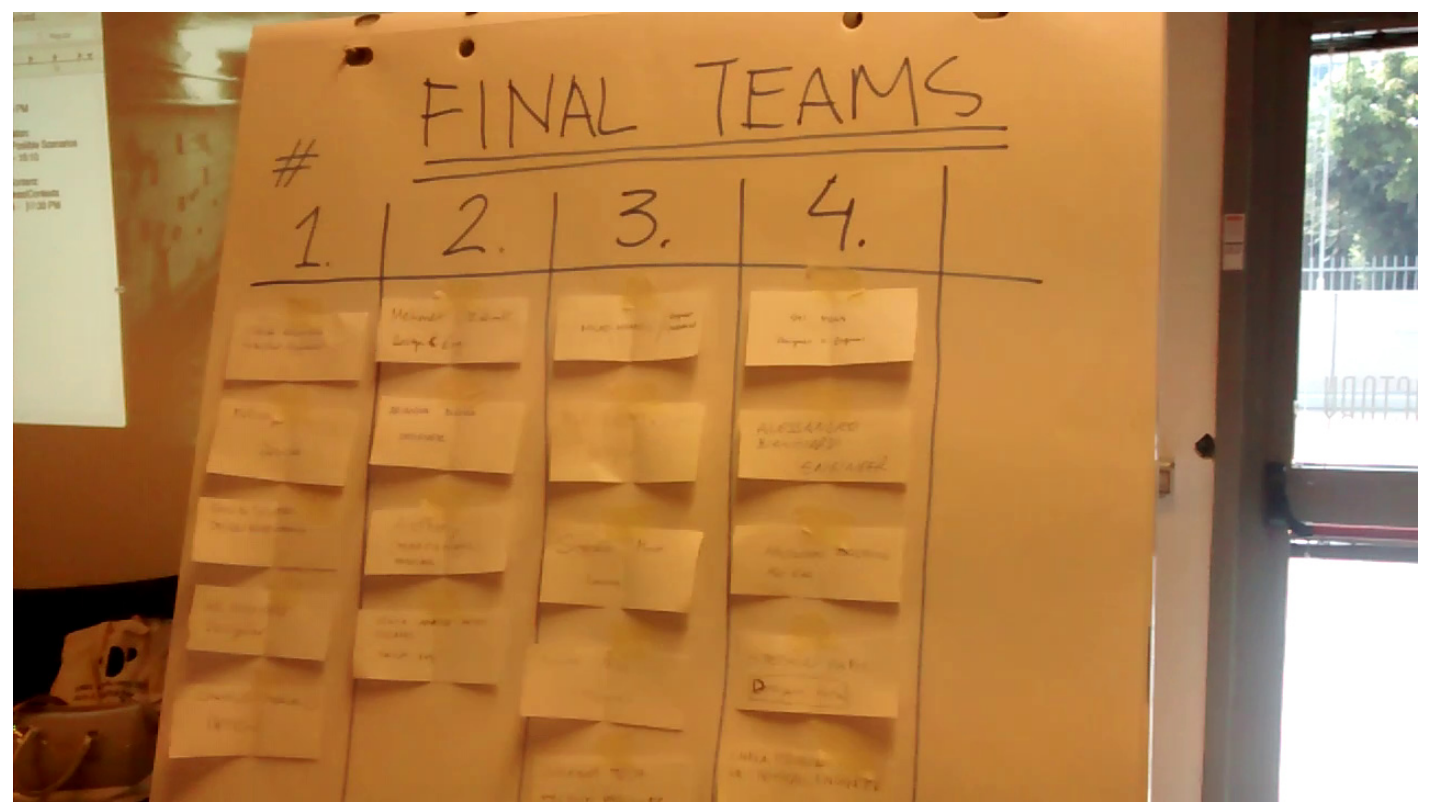

Figure 5. Four multi-disciplinary design teams were formed 

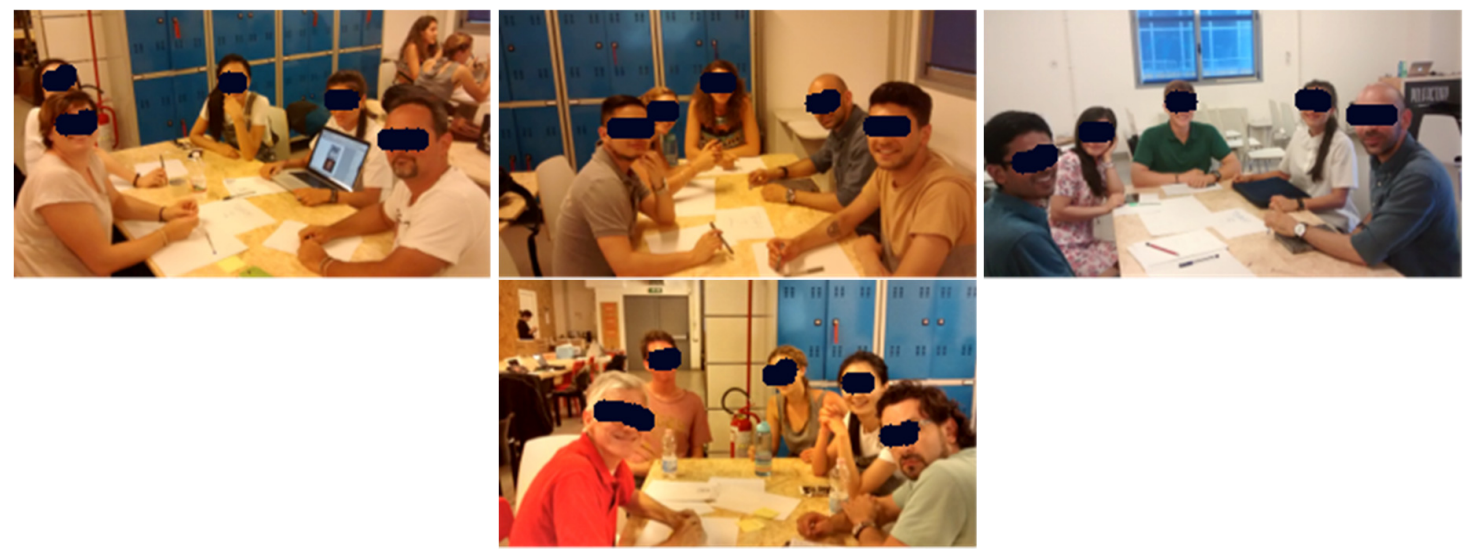

Figure 6. Teams nr. 1 - 2 - 3 - 4 (incl. teaching expert)

\subsubsection{VRPT-SS design studio setting and multi-disciplinary design teams}

The design environment or -space where design-activities take place is very important, especially when fast and speedy processes are set-off against slow and reflective processes (Figure 6). The lay-out and utilities (i.e. web access, robust WIFI), a plethora in prototyping tools (e.g. hand-, machine-, 3-D printers), design tools (e.g. traditional and digital) and a wide variety in ready-available materials are crucial ingredients to support and assist designers to create successful design engineering processes for consumer products (Figure 7). The school was held in the Polifactory laboratory located at the Politecnico di Milano (www.polifactory.polimi.it).
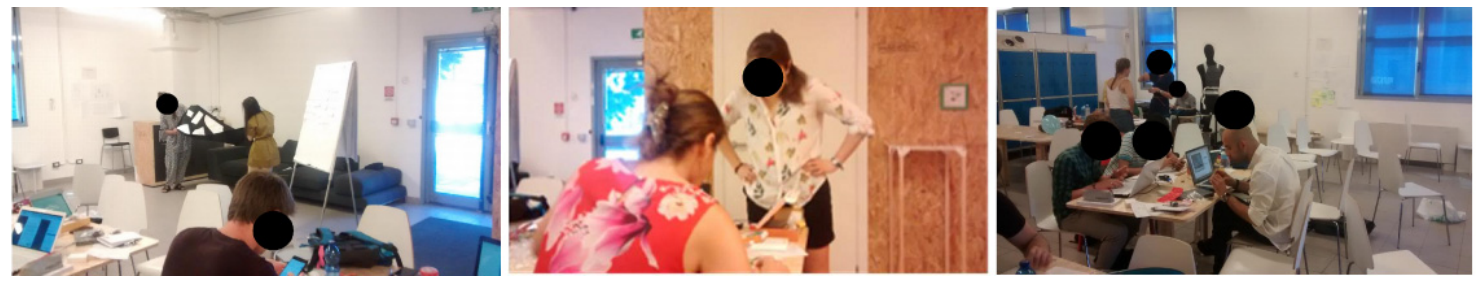

Figure 7. VRPT Studio setting with team-work in an agile and loosely-fitted mode

\subsection{Design methodology and process}

In fact, there was not an underlying predefined method or methodology for the VRPT-SS. Aside from the program with lectures from domain-experts and a company executive, the sequence of activities stemmed from a rather bottom-up holistic approach (Figure 8) (Wendrich, 2010). Instead of following a strict formative linear approach to a design process, the teams could set-off on their own direction and follow their concurrent path to direct the problem-solving strategy. This Way Of Working (WOW) supports and facilitates the free exploration, investigation and manifestation of iterative content creation (Brereton, 2010), next to enhancement of communication flow (Csikszentmihalyi, 2014), enrich associative reasoning and opening up transgressions between the multiple disciplinary stakeholders (see Osborn, 1953; Koestler, 1964). 

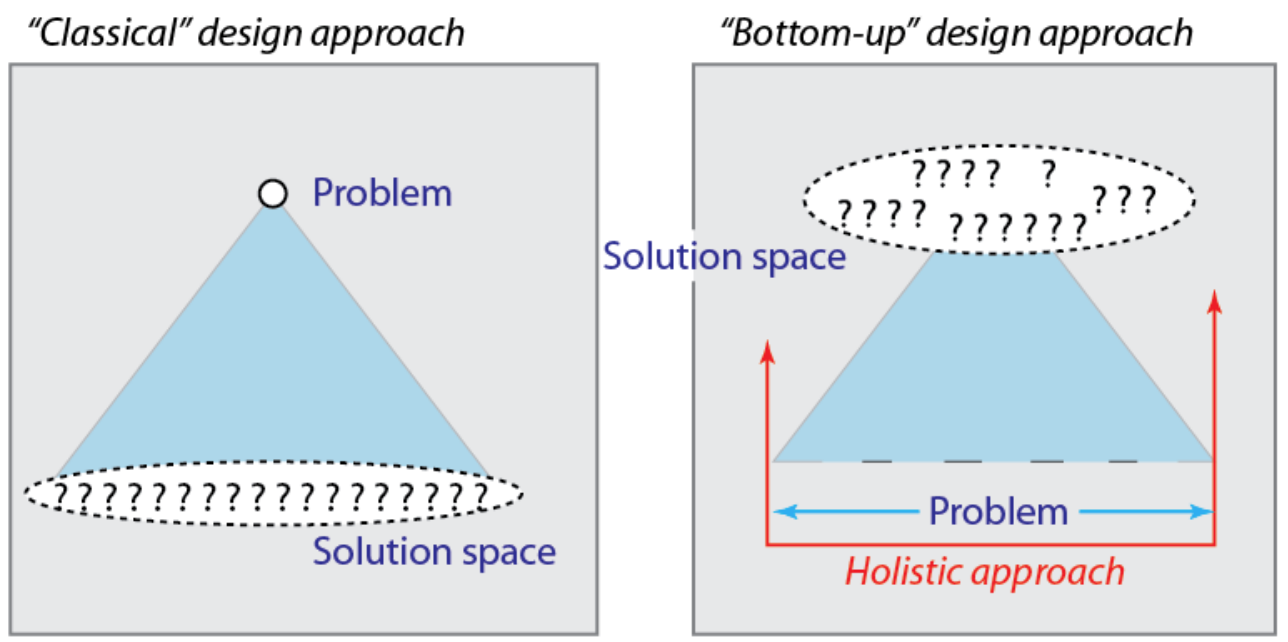

Figure 8. "Bottom-up" design approach (Wendrich, 2010)

\subsubsection{Ideation phase (fuzzy-front end)}

Each team started to analyse and evaluate the design task by taking notes, sketching-out requirements, externalizing the early ideas following a divergent-convergent creative iteration process (Wendrich, 2013). Next to this they were directed to use a simple step-by-step procedure that enabled them to creatively execute Step 1: generate as many iterations (i.e. quick and fast ideas) as possible, followed up by Step 2: association and positioning of possible ideas to fit-to-purpose, Step 3: abstraction of ideas to form concepts/themes to fit context(s) and evolve towards the final Step 4: representation of possible and/or potential solutions to fit the requested problem of the design task (Wendrich, 2015). Subsequently the creation and visualization of the final concepts were formulated, prototyped, and presented in a final project presentation. Every team had their own concept-ideation project wall, here they could post and position all their sketches, material samples, diagrams and all other information in relation to their project (Figure 9).

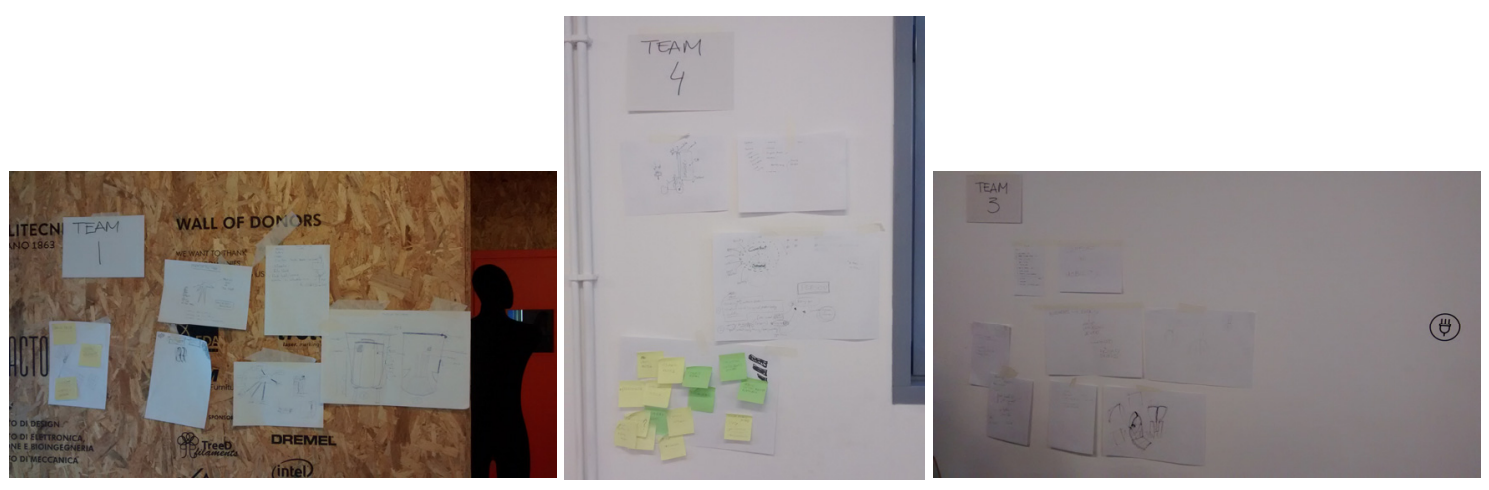

Figure 9. Concept-ideation project walls of the various teams

\subsubsection{Conceptualization phase, virtual and physical prototyping}

Virtual and physical prototyping is recognized and regarded as a practice useful for the reduction of the development costs of industrial products. Such prototypes are anticipation of a product shapefunction that does not exist in reality yet, but that appears and behaves as it were real. Therefore, virtual and physical prototypes simulate the imagination and visualization in how a future productidea looks, functions and how it works. Furthermore, prototypes can be used to test how users use the 
thing in praxis, apply usability within prospective context, try-out various functions and features (Figure 10).
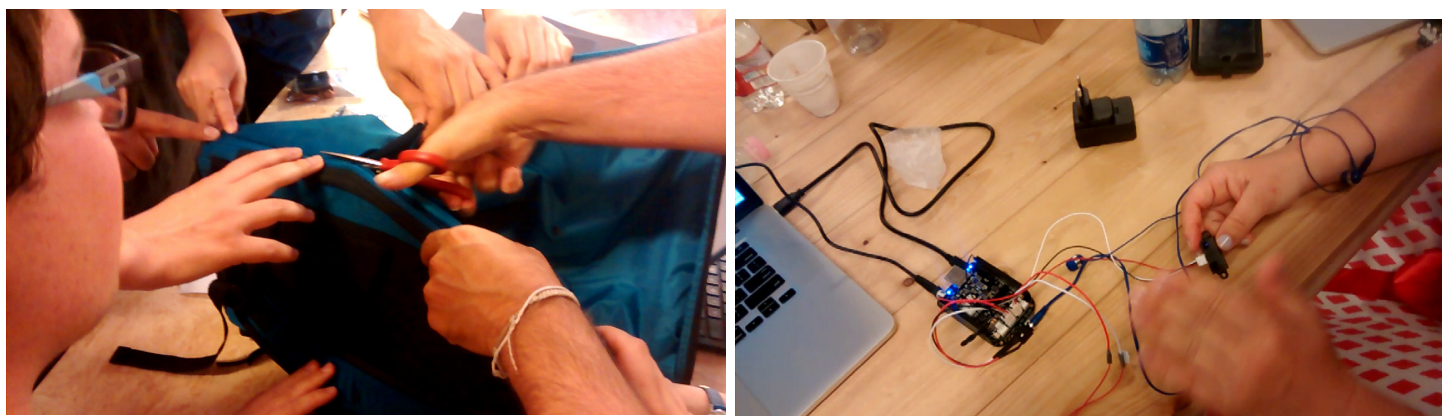

Figure 10. Prototyping physical tinkering and virtual hacking

To interact with the virtual and physical prototypes thus becomes multi-dimensional, experiential, multisensory and multimodal. Research outcomes of recent years and the enormous improvements in price and performances in ICT technology have enabled the realization of complex prototypes integrating real-time, immersive, mixed or augmented, visual interaction, as well as haptic, sonic and olfactory interaction (Figure 11). Creating effective physical and virtual prototypes requires interdisciplinary skills, which go beyond engineering and IT disciplines, and include crucial disciplines related to human aspects such as human factors, human perception, human cognition and creative design engineering (Figure 12).
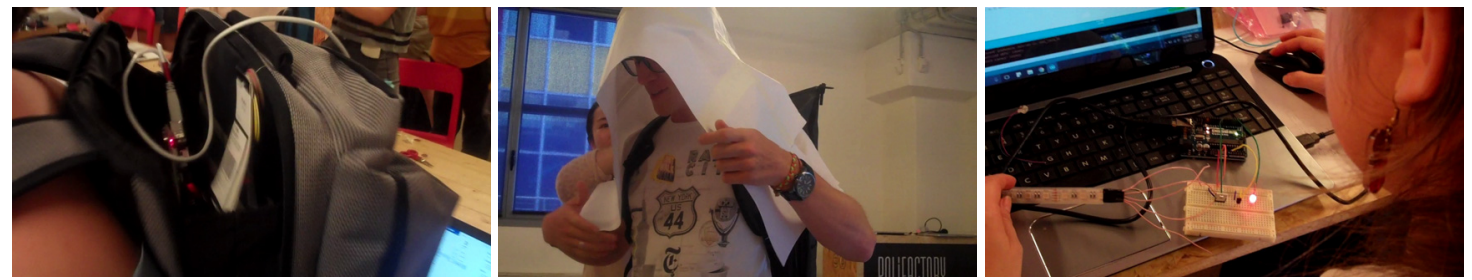

Figure 11. Multi-sensorial integration, application, and building early stage prototypes with MR
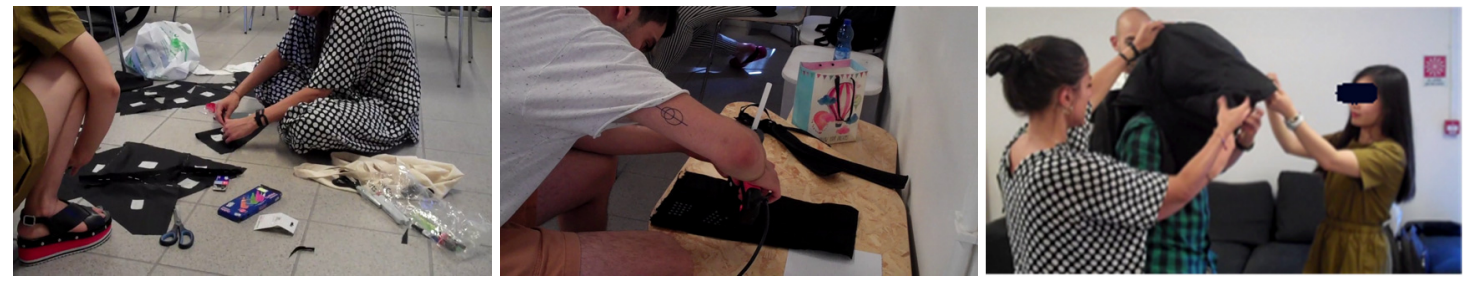

Figure 12. Final prototype construction and assembly

\subsubsection{Final representation and presentation}

On the final day all four teams were to present their final concepts and demonstrate their prototypes to the teaching experts and other participants of the VRPT-SS. The representation and presentation of the projects was very lively and dynamic, in some cases the context and experience were laid out in a 'makebelief' video in conjunction with the use of smart-pone apps, integrated sensors, electronic devices and story-telling (Figure 13). 

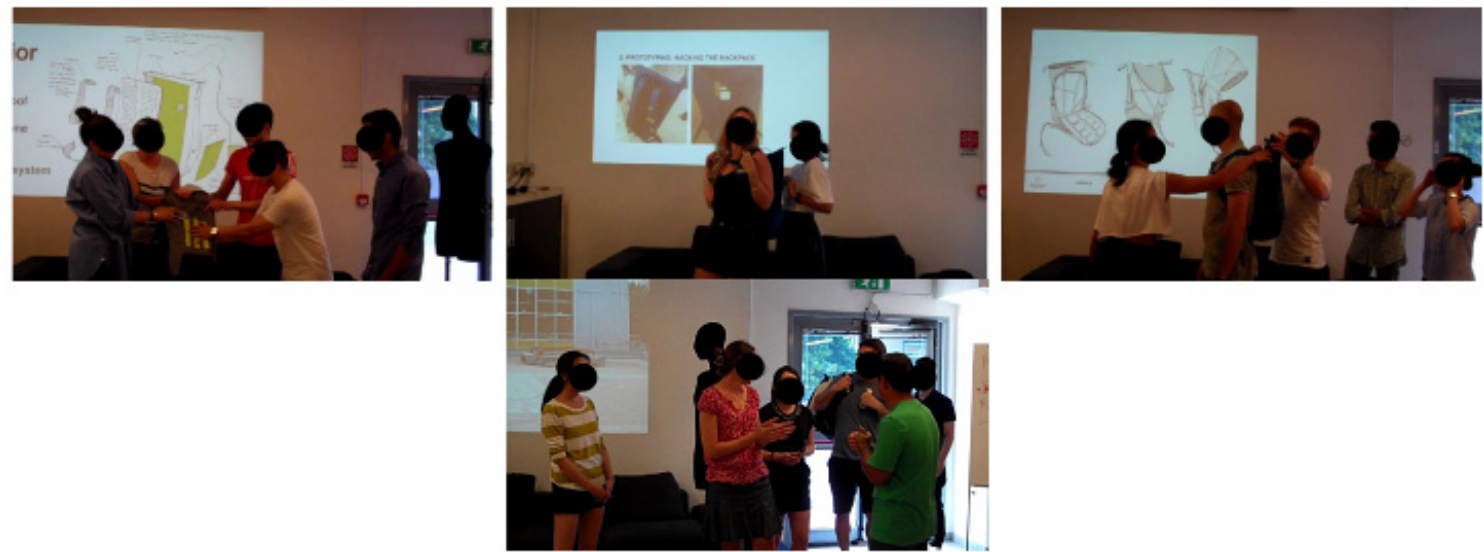

Figure 13. Final team presentations of product concepts

Other presentations used multiple actors to enact (i.e. narrative) the envisioned scenario(-s) within the specified context to illustrate the working and expected experience of the backpack. Most teams supported their presentation with a slide-show, incorporating images, sound and video from their prototyping and PDP (Figure 14).
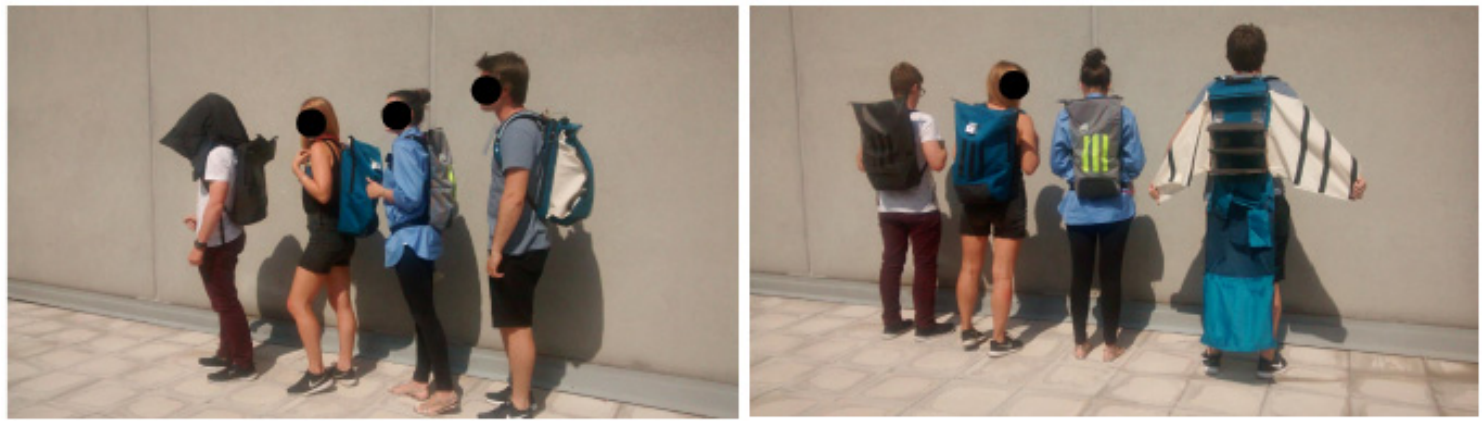

Figure 14. Four teams, four prototypes, four contexts, four configurations, four novel concepts of backpack consumer products and services

\subsubsection{Projects and process analysis and evaluation}

During the studio-sessions, the lecturers and the instructors monitored the progress of the projects by providing suggestions, if necessary. In addition, the teachers or tutors provided technical support, particularly regarding haptic and sound technologies. Students were asked periodically to show the results of the project they were carrying out and to demonstrate the functioning of their concept, acting as if the prototype worked, even before creating a true working prototype.

At the end of the studio, students were asked to prepare a group presentation in which the project results were shown to the course lecturers and instructors. The presentation was a combination of slides with pictures movies and also a practical demonstration of the prototype. During the presentation, the audience could ask questions, express doubts and comments.

After all the presentations and questions and answer period, the lecturers and instructors met to decide and discuss the results of the projects. The projects were evaluated mainly on the basis of the following parameters:

- level of originality of the idea;

- quality of the prototyping activity.

Concerning the originality of the idea, the evaluation by the company was not required. The VRPT-SS was purely educational. 
The company provided positive feedback on the way the school was held and the quality of the results obtained. The design approach has been evaluated particularly effective allowing students with fresh minds on the target product to develop innovative and interesting concepts in a short time.

\section{Results and findings VRPT-SS}

The final results, four prototype backpacks based on a contextualized-experience, to be an engaging and multisensory device, product or service were executed and delivered within the given timeframe. Overall the results were satisfactory to good, in some cases the product or service concept were considered very interesting. The mixed approach in physical and virtual prototyping to convey a functional concept or usability idea proved to be very successful. The combination and integration of multiple realities with hardware, software, presentation and representation modalities lead to rich and enticing experiences (see for example Campbell et al., 2016). The illustrative imagery, illusionary effects, tactile-tangible feedback and 'make-belief' settings in conjunction with play and storytelling enhanced the scope of the envisioned project (see also Nakevska et al., 2017).

\section{Conclusion}

To conclude the VRPT-SS and mixed reality prototyping was a great success. All participants had a good time working together on a collaborative design-task in a multi-disciplinary setting. The inclusion and encapsulation of supportive experts helped in the agile approach of the PDP, as well as in the timely assistance and intervention during the prototyping and other design task executions. An open design space and free access to all the tools and materials needed to further the process helped in the overall final results of the projects. Moreover, the collaborative and cooperative attitude and flexible behaviour of all the stakeholders (i.e., experts, students, facilitators) during the five-day sessions enriched the communication, supported the variety and diversity in perspectives and created a vibrant, dynamic, and lively design experience environment. In the analysis and evaluation of the captured videos and photos we observed playful interaction, fun, creative freedom, and an open sharing work climate, where all participants could externalize their ideas and convey their thoughts without restraints. To start a PDP with a real-world design brief and task helped to fundament a professional setting. In conjunction with the variety in expert lectures and ready available know-how on demand the VRPT-SS design studio proved to head off in the right direction for the near future. For the next edition(-s) of the VRPT-SS more emphasis will be put on for example; feasibility of prototypes (i.e. usability, function, production and manufacturability), interaction design and modelling (IxD), context application, coding and product integration of electronic- and embodiment design in conjunction with 3D-AM technologies.

\section{Acknowledgement}

The authors would like to thank all the people who contributed to the success of the VRPT-SS including: teachers, students, tutors and the Adidas company for providing the case study and interesting input.

\section{References}

Alterator, S., Deed, C. and Prain, V. (2017), "Encapsulating teacher expertise in action", Teachers and Teaching, pp. 1-11. https://doi.org/10.1080/13540602.2017.1399874

Boelens, R., De Wever, B. and Voet, M. (2017), "Four key challenges to the design of blended learning: a systematic literature review", Educational Research Review, Vol. 22, pp. 1-18. https://doi.org/10.1016/j.edurev.2017.06.001

Bordegoni, M. and Ferrise, F. (2013), "Designing interaction with consumer products in a multisensory virtual reality environment", Virtual and Physical Prototyping, Vol. 8 No. 1, pp. 51-64. https://doi.org/10.1080/17452759.2012.762612

Brereton, M.F. (1999), "Distributed cognition in design: negotiating between abstract and material representations", Proceedings of DTRS'99 / the $4^{\text {th }}$ International Design Thinking Research Symposium on Design Representation, Cambridge, Massachusetts, April 23-25, 1999. 
Buchenau, M. and Suri, J.F. (2000), "Experience prototyping”, Proceedings of DIS'00 / the $3^{\text {rd }}$ conference on Designing interactive systems: processes, practices, methods, and techniques, New York, USA, August 17-19, 2000, ACM, New York, USA, pp. 424-433. https://doi.org/10.1145/347642.347802

Campbell, A.G., Santiago, K., Hoo, D. and Mangina, E. (2016), "Future mixed reality educational spaces", Proceedings of FTC 2016 / Future Technologies Conference, San Francisco, USA, December 6-7, 2016, IEEE, pp. 1088-1093. https://doi.org/10.1109/FTC.2016.7821738

Csikszentmihalyi, M. (1996), Creativity: Flow and the psychology of discovery and invention, Harper Collins, New York.

Ferrise, F., Graziosi, S. and Bordegoni, M. (2017), "Prototyping strategies for multisensory product experience engineering", Journal of Intelligent Manufacturing, Vol. 28 No. 7, pp. 1695-1707. https://doi.org/10.1007/s10845-015-1163-0

Koestler, A. (1964), The act of creation, Hutchinson, London.

Muraida, D.J. and Spector, J.M. (1992), “The advanced instructional design advisor", Instructional Science, Vol. 21 No. 4, pp. 239-253. https://doi.org/10.1007/BF00128494

Nakevska, M., van der Sanden, A., Funk, M., Hu, J. and Rauterberg, M. (2017), "Interactive storytelling in a mixed reality environment: the effects of interactivity on user experiences", Entertainment Computing, Vol. 21, pp. 97-104. https://doi.org/10.1016/j.entcom.2017.01.001

Osborn, A.F. (1953), Applied imagination, Charles Scribner's Sons, New York.

Wang, G.G. (2002), "Definition and review of virtual prototyping", Journal of Computing and Information Science in Engineering, Vol. 2 No. 3, pp. 232-236. https://doi.org/10.1115/1.1526508

Wendrich, R.E. (2010), "Raw shaping form finding: Tacit tangible CAD", Computer-Aided Design and Applications, Vol. 7 No. 4, pp. 505-531. https://doi.org/10.3722/cadaps.2010.505-531

Wendrich, R.E. (2013), “The creative act is done on the hybrid machine”, Proceedings of ICED'13 / the 19th International Conference on Engineering Design, Vol. 1: Design Processes, Seoul, Korea, August 19 - 22, 2013, pp. 399-408.

Wendrich, R.E. (2015), "Integrated Creativity and Play Environments in Design and Engineering Processes", Proceedings of ASME 2015 International Design Engineering Technical Conferences and Computers and Information in Engineering Conference, Boston, Massachusetts, USA, August 2-5, 2015, American Society of Mechanical Engineers, pp. V01BT02A055. https://doi.org/10.1115/DETC2015-47214

Zorriassatine, F., Wykes, C., Parkin, R. and Gindy, N. (2003), "A survey of virtual prototyping techniques for mechanical product development", Proceedings of the institution of mechanical engineers, Part B: Journal of engineering manufacture, Vol. 217 No. 4, pp. 513-530. https://doi.org/10.1243/095440503321628189

Francesco Ferrise, Associate Professor

Politecnico di Milano, Department of Mechanical Engineering

Via la Masa 1, 20156 Milano, Italy

Email: francesco.ferrise@polimi.it 